\title{
LOSS OF CONSCIOUSNESS DURING SPONTANEOUS LAUGHTER
}

\author{
Stanisław DEC \\ Neurology Clinic, Environmental Neurophysiology Laboratory, Military Institute of Aviation Medicine, \\ Warsaw, Poland
}

Source of support: Own sources

Author's address: S. Dec, Military Institute of Aviation Medicine, Krasińskiego 54/56 Street, 01-755 Warsaw, Poland, email: sdec@wiml.waw.pl

Abstract: The patient reported to the Neurology Clinic because of tetanic seizures occurring during spontaneous laughter. The patient is 29 years old, right-handed, of proper body build and nutrition, free of cardiovascular and hormonal disorders, with regular menstrual cycle, a psychologist by education. During the last four weeks (November-December), she had five irregular, repetitive episodes of sudden generalized weakness, lasting up to 5 minutes, at different times of the day (except night time). In 2-3 minutes, each time a few seconds of a state of "zoning out" (loss of consciousness) occurred [5,12,15]. All episodes appeared during a dozen or more seconds of spontaneous laughter, when in the company of close ones. The patient was diagnosed with latent tetany on the basis of subjective and physical neurological examination, additional examinations, positive reaction to the treatment applied, and after excluding other medical causes.

Keywords: laughter, hyperventilation, tetany, loss of consciousness, QEEG 


\section{INTRODUCTION}

Laughter is produced mainly by the contraction of the facial muscles and the characteristic voice that usually accompanies it. It is often accompanied by more or less expressive, theatrical behavior depending on the temperament of the person, the purpose and the situation. Laughter has been described for centuries in various ways and forms, especially by writers and bards. Very often, people with a high self-esteem and a good humor are able to "infect" those in their company with laughter, making fun of their own weaknesses in particular. These people are the so-called spiritus movens. Laughter toned with mockery is aimed at abasement or humiliation - in such case everyone experiences it in their own way. Apart from a positive or unpleasant emotional charge, laughter can be a symptom of an illness or an illness itself. For example, a sardonic grin which accompanies tetanus is actually caused by the contraction of facial muscles exposing one's teeth in such an expression. Another example of illness-based laughter is paradoxical laughter (paragelia, gr. para - inappropriate, gelia - laughter) - a paroxysmal, spontaneous laughter of a very high intensity, unwarranted by the moment and situation. Very often it is difficult to control. It is seen by outsiders as indecency, lack of empathy, a kind of malice. Schizophrenia in adults and autism in children predisposes to such kind of laughter. Epilepsy can manifest itself through episodes of uncontrollable laughter, mainly in children $[14,15]$. In psychoorganic syndrome of postapoplectic or posttraumatic origin (cerebral contusion), individuals with weakened affect control mechanisms and pseudobulbar affect often experience episodes of uncontrollable laughter alternating with crying. Laughter may often trigger dyspnoea in patients with asthma (the author's experience from work in Emergency Ambulance Service). In children (emotional and bioelectrical immaturity of the brain), during spontaneous and/or expressive laughter, temporary sphincter dysfunctions (mainly of urinary bladder) are sporadically observed.

\section{DIAGNOSTICS}

\section{Clinical condition}

Patient I. O., maiden, age 29, only daughter, height $171 \mathrm{~cm}$, body weight $76 \mathrm{~kg}$, proper body built and nutrition, right-handed, free of cardiovascular and hormonal disorders, with regular menstrual cycle - 28/4. Currently at the end of 2nd phase of the menstrual cycle (24th day). She has not been pregnant and is not pregnant now (as of 4 December 2014). systematically undergoes gynecological check-ups (most recently two months ago - no problems were found). Not undergoing long-term treatment or have not undergone intermittent treatment (taking medication) or used specific diets within the last five months. No addictions. Academic teacher, psychologist by education. No family, social or legal conflicts. Full, logical, spontaneous communication. Natural, correct behavior. No history of significant past and present illnesses, especially head injuries, family and inherited diseases and other ailments was determined. Cares for good psychophysical fitness. Does body conditioning gymnastics and jogs (several kilometers) in her free time. Parents are healthy, with no significant past medical history or systemic disorders. She reported to the Neurology Clinic because of five irregularly repeated episodes over the last four weeks of sudden feeling of generalized weakness, with the impression of "being-close" to fainting, accompanied by formication around the mouth and fingers. With the tendency for fingers of both hands to become stiffened in a spread position. Lasting up to 5 minutes (?), at different times of day (except for night time). In 2-3 minutes, each time a few seconds of a state of "zoning out" (loss of consciousness) occurs. According to the reports of family and friends (witnesses), for a few seconds during an episode she barely reacts or does not react at all when spoken to, her eyes are open but the gaze is "absent", her lips are (slightly) tightened. Each time her complexion turns pale, but not cyan. Slight (?) tremor of upper limbs and lower limbs. Moisture level of the skin not increased. During an episode, she does not perform uncoordinated movements, no stereotypy, does not say any words and does not produce inarticulate vocal sounds. She does not foam at the mouth and does not demonstrate unconventional behavior. All the episodes, except for the fourth one (in order of occurrence), occurred in different places, always in the company of friends, in a good friendly mood (without substance use), interspersed with a lot of spontaneous, expressive laughter. Because of the known uncomfortable consequences of laughter (repetition of prodromal symptoms of the started laughter), despite self-control, the patient claims that she could not stop the process. It was followed by "forced uncontrollable laughter" until the rest of the course of the event was no longer registered by memory [12]. The state of forced laughter evoked in the patient's consciousness the feeling of fear/threat of the subsequent course of the 
starting episode. Only the "fourth" episode occurred when the patient was alone at home, in the evening. In a state of general well-being and complete relaxation, sitting (reclining position) and enjoying ordinary green tea, not using other substances. A sudden feeling of weakness with subsequent momentary "zoning out" occurred during "moderate" spontaneous laughter while watching comedy sketches on television.

After each episode, the patient had a slight buzzing sensation in the ears lasting for a few minutes, a feeling of uncertainty as to full visual and motor coordination and perception of the environment, accompanied by anxiety. She did not feel sleepy, tired, sore (without signs of lip biting, tongue biting) and did not indicate any temporary sphincter dysfunctions. She did not feel cold, hungry, thirsty, or have other urgent physiological needs. The patient says she sleeps regularly. She sleeps a min. of 6-7 hours at night. In case of every episode, she had a good night sleep, was rested and relaxed. Before and in the meantime, there were occasional social gatherings full of spontaneous laughter and excellent mood, and the patient had many other occasions to laugh spontaneously, but without a highly expressive, emotionally intensive, spontaneous laughter. The "series of laughter" in these cases were shorter in duration and did not exceed several seconds.

\section{Diagnostic tests}

The physical examination indicated: BP $125 / 75 \mathrm{mmHg}$ in the left upper limb and 124/73 $\mathrm{mmHg}$ in the right upper limb, HR - 78 bpm, vessels in both the upper limbs and the lower limbs well tensioned and filled, consistent with the heart activity. The skin is clean, properly tight and elastic, with no signs of increased dermatographic urticaria. Rhythmic heart activity, clear, loud sounds. Free breathing through the nose. Normal vesicular sound. No abnormalities in the lungs (no signs of edema). Thyroid gland was not palpable during examination. Tongue, oral cavity, uvula and throat - no abnormalities. Peripheral lymph nodes were palpable - no abnormalities. Palpation of abdominal organs excluded abnormalities. Costovertebral angle tenderness - negative on both sides. Romberg's test - negative. No abnormalities in cranial nerves and peripheral nerves. No Chvostek signs, Lust signs, Trousseau signs of latent tetany or pyramidal and extrapyramidal symptoms. Examination of the reaction to stimuli of eyes and hearing excluded abnormalities.

The patient was referred for additional examinations. Blood morphology, determination of ESR,
INR with biochemical indicators (sugar, urea, creatinine, total bilirubin, liver function test, ALAT, ASPAT and GGT). Total HDL and LDL cholesterol, triglycerides, TSH, PTH, electrolyte levels; $\mathrm{Na}, \mathrm{K}$, $\mathrm{Ca}, \mathrm{Mg}$ and Fe. Vitamins B12 and D3). General urinalysis. EEG, ECG, Cardiac and Thyroid ultrasound, EMG (ischemic test for tetany). Additional periodic examinations carried out two months ago: blood morphology, ESR, ECG and chest X-ray, the results of which were provided by the patient, show no abnormalities. It was recommended to minimize the intensity (expressiveness) of laughter in situations provoking and conducive to laughter. On the second day, a QEEG was carried out in the time before noon (9-10 o'clock). The patient was prepared for the test - she was well-rested, had breakfast, was in good psychological and physical condition. QEEG reading - borderline normal, with cardiac and muscular artifacts (Fig. 1a-1d).

\section{Laboratory tests}

So far, the patient has underwent the following additional examinations: 1) blood morphology (on 15 December 2014 - 8th day of menstrual cycle); ESR - $9 \mathrm{~mm} / \mathrm{h}$, INR - 1.1, RBC - 4.3 x 1012/l, WBC $-9.8 \times 109 / \mathrm{l}, \mathrm{Hb}-8.9 \mathrm{mmol} / \mathrm{l}$, blood sugar: $4.2 \mathrm{mmol} / \mathrm{l}$, total bilirubin $-11 \mu \mathrm{mol} / \mathrm{l}$, urea -5.1 $\mathrm{mmol} / \mathrm{l}$, creatinine $-81 \mathrm{mmol} / \mathrm{l}$, total cholesterol - $41 \mathrm{mmol} / \mathrm{l}$, triglycerides $-0.91 \mathrm{mmol} / \mathrm{l}, \mathrm{Na}-137$ $\mathrm{mmol} / \mathrm{l}, \mathrm{K}-4.9 \mathrm{mmol} / \mathrm{l}, \mathrm{Ca}-2.2 \mathrm{~m} \mathrm{~mol} / \mathrm{l}$ (lower limit), $\mathrm{Mg}-0.8 \mathrm{mmol} / \mathrm{l}, \mathrm{Fe}-156 \mu \mathrm{g} / \mathrm{dl}, \mathrm{TSH}-1.19$ $\mathrm{mlU} / \mathrm{L}, \mathrm{PTH}-5.1 \mathrm{pmol} / \mathrm{l}$, vit. B12 - $465 \mathrm{ng} / \mathrm{l}$, vit. D3 - $59 \mathrm{nmol}$. Other parameters within normal limits. 2) General urinalysis within normal limits. 3) ECE within normal range. EMG (26 January 2015) - ischemic test - low positive. Thyroid ultrasound (9 February 2015) - no noticeable abnormalities. Echocardiogram - the examination was not carried out.

\section{TREATMENT}

After the examinations, the following medications were recommended: 1) Calperos - $500 \mathrm{mg}$ caps. at a daily dose of $2500 \mathrm{mg}$, according to the administering scheme $|2-2-1|$ during a meal and 2) Tegretol CR 200, starting from $1 / 2$ pill in the morning for three days. Then, increasing by $1 / 2$ pill every three days, reaching a dose of $2 \times 200 \mathrm{mg}$ per day according to the administering scheme |1-0-1|. A check-up with the results of requested additional medical examinations (if possible) was scheduled in three weeks' time. After one month of taking the above medicines, the patient came in for a check-up in good general health, register- 
ing no complaints. In the meantime she was not ill, she did not take any other medicines than the above two - according to the recommended administering scheme. During this time, despite she was aware of the need of moderation in the intensity of spontaneous laughter, one episode occurred (after 3 weeks of treatment) with the same course as described above, when laughing her head off with her friends.

After 6 months since the last event, without the above mentioned symptoms, in July 2015, the patient stopped taking Calperos on her own. She continued treatment with Tegretol CR 200 at a daily dose of $400 \mathrm{mg}(2 \times 200 \mathrm{mg})$. Due to the disappearance of the symptoms, the patient stopped attending medical (neurological) appointments. The contact was limited to the provision of short telephone information on general health (approx. 1 x per quarter). In November 2016, she came in for a follow-up appointment - in general good health, registering no complaints and no episodes since the end of December 2014. A follow-up QEEG was carried out and the reading was within norm, showing no muscular artifacts, with cardiac artifacts. Results of some additional tests (October-November 2016); Ca - $2.4 \mathrm{mmol} / \mathrm{l}, \mathrm{Mg}-0.9$ $\mathrm{mmol} / \mathrm{l}, \mathrm{Mg}-0.9 \mathrm{mmol} / \mathrm{l}$, vit. D3 $-79 \mathrm{nmol} / \mathrm{l}, \mathrm{TSH}$ $-1.20 \mathrm{mlU} / \mathrm{L}$. Other results of additional tests, i.e. blood morphology with "biochemistry", general urinalysis, ECG and chest X-ray - within norm. No results of the PTH levels. Gynecological consultation - no abnormalities. After consulting with the patient, gradual reduction of the amount of Tegretol CR 200 taken by $1 / 4$ every month $(4 \times 1 / 4)$ was recommended. Telephone contact with the patient was maintained. The recent telephone call to the patient did not provide any negative information about her general state of health. The patient is feeling fine. She remembers about the moderation in spontaneous laughter and that "laughter can be no laughing matter".

\section{QEEG examinations}

Figures 1a to 1d illustrate selected fragments of QEEG No. 014150, recorded on 05 December 2014, on the 25th day of the patient's menstrual cycle, between 9 and $10 \mathrm{am}$. The EEG basic activity was maintained. The QEEG analysis is dominated

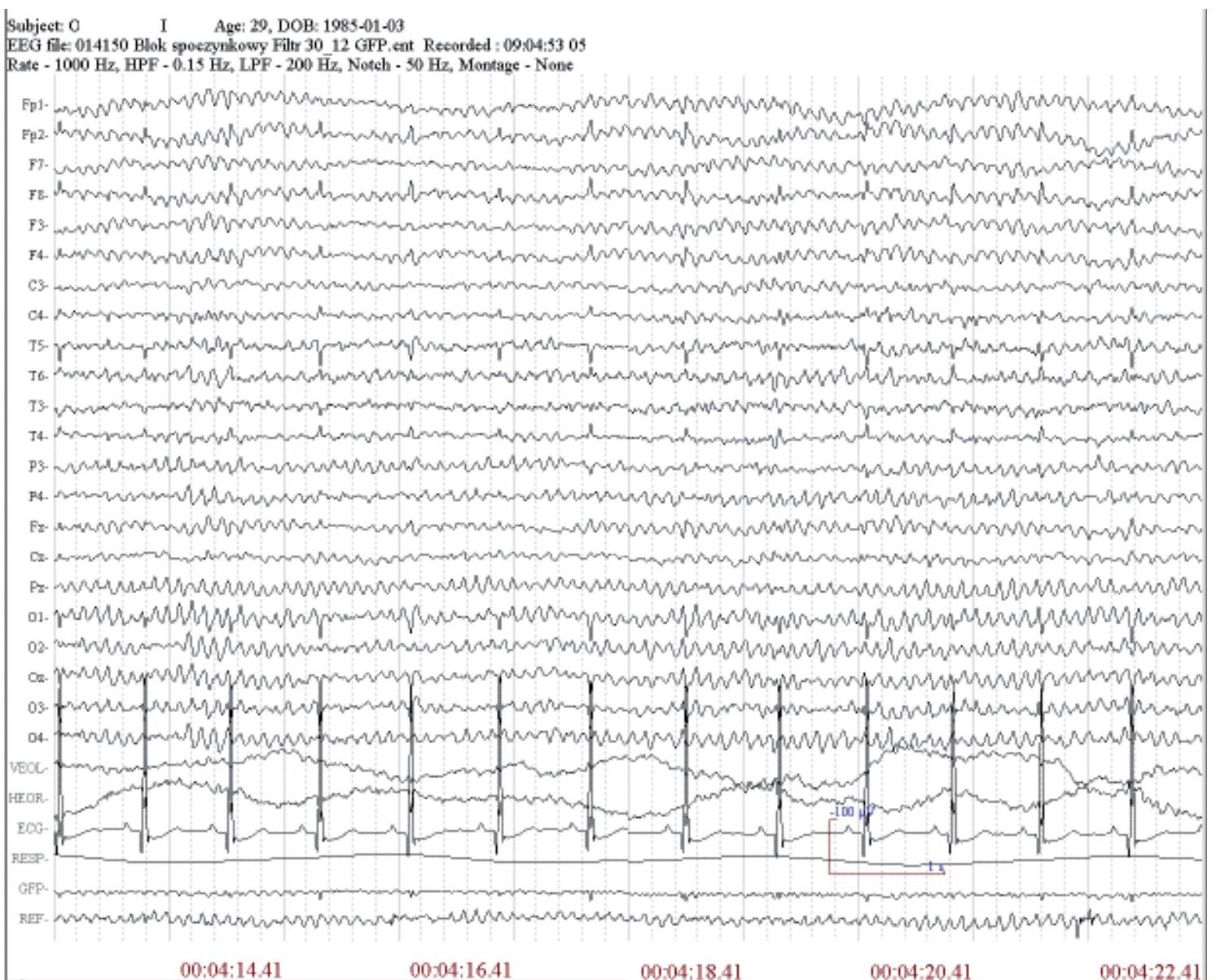

Fig. 1a. QEEG examination. Fragment of resting EEG No. 014150 of 5 December 2014 
Dec S. - Loss of consciousness...

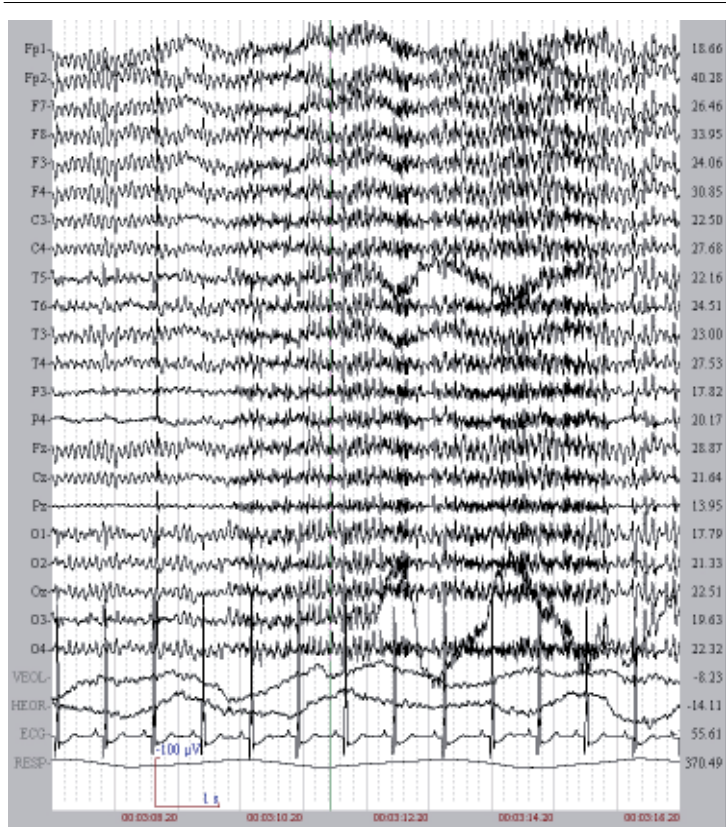

Fig. 1b. QEEG examination. Fragment of resting EEG No. 014150 of 5 December 2014. The beginning of a series of generalized muscular artefacts, EMG - similar.

by alpha rhythm of $9.8 \mathrm{~Hz}(8.5-9.5 \mathrm{~Hz}$ frequency range - visual assessment) with amplitude up to $30 \mu \mathrm{V}$ and peaks up to $40 \mu \mathrm{V}$ in the middle and posterior temporal areas of the left cerebral hemisphere and contains low voltage beta activity. Alpha activity maintained. Against this background, a few single waves of $7.5-8 \mathrm{~Hz}$ with an amplitude within the background, without seizure characteristics, were recorded in the front and middle temporal areas of the left cerebral hemisphere. Regardless of the above-mentioned changes, quite numerous muscular artifacts - series of very rapid generalized EMG waves were recorded - similar ones with amplitude up to $40 \mu \mathrm{V}$ (fig. 1b, 1c, 1d). Figures $1 \mathrm{~b}$ and 1c illustrate the beginning and end of a muscular artifact in the form of a generalized series of rapid EMG activity - similar. During hyperventilation (fig. 1d) the number of generalized fast wave series (EMG similar) with amplitude $<40 \mu \mathrm{V}$ increased. After which in all leads an acceleration of the alpha rhythm by $1.5-2 \mathrm{~Hz}$ (fig. 1c), for 6-7 seconds occurs. After this time, the alpha rhythm normalizes, returns to the previous frequency, i.e. 8.5-9 $\mathrm{Hz}$. Stimulation with single intermittent white light flashes, with a frequency of 2, 6, 12 and 18 $\mathrm{Hz}$, did not trigger the bioelectric activity of the brain, it did not change the character of EEG recording. The EEG contains cardiac artifacts, consistent with heart activity.

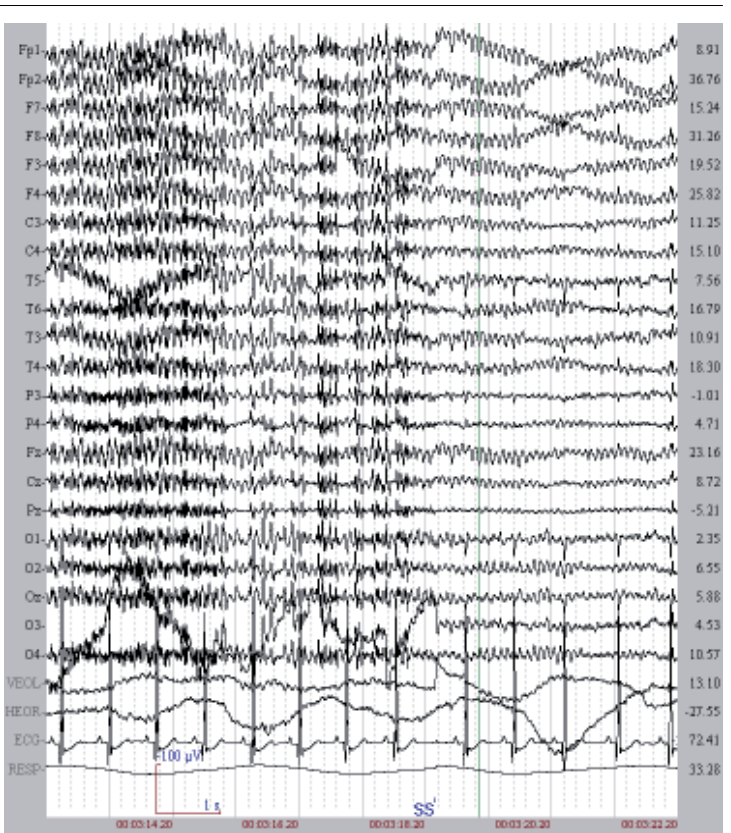

Fig. 1c. QEEG examination. Fragment of resting EEG No. 014150 of 5 December 2014. The end of a series of generalized muscular artefacts, EMG - similar, with subsequent (transient) acceleration of the alpha rhythm by $1.5-2 \mathrm{~Hz}$.

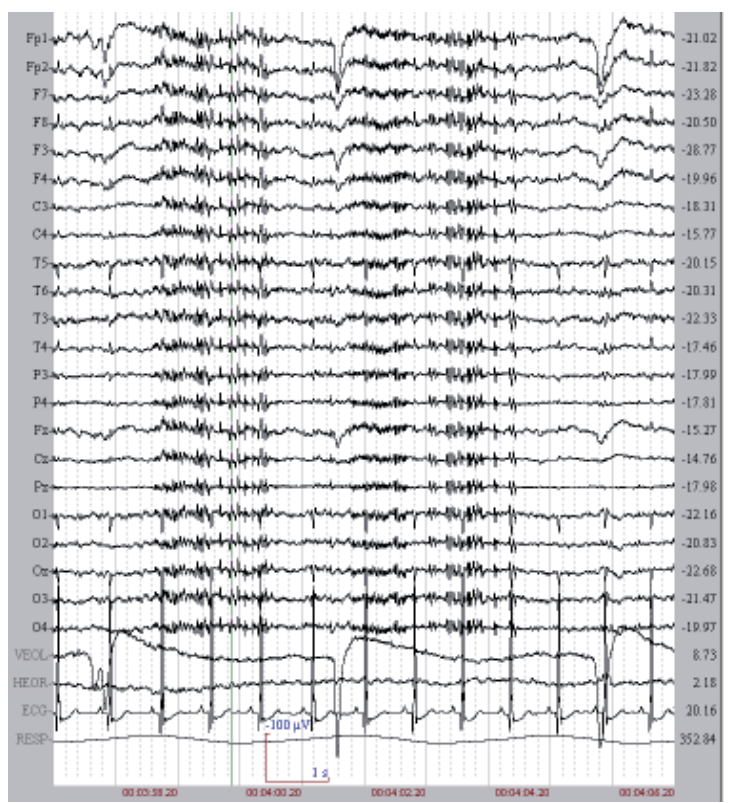

Fig. 1d. QEEG examination. Fragment of resting EEG No. 014150 of 5 December 2014. The beginning of hyperventilation. Generalized fast activity artefacts, EMG - similar.

Figure 2 illustrates a selected fragment of the follow-up QEEG No. 016070 examination carried out on 14 November 2016 between 10 and 11 a.m. on the 25th day of the menstrual cycle, due to the decision to gradually reduce the dose by $1 / 4$ over a four-month period until the complete discontinuation of the Tegretol CR 200 treatment, with the current daily dose of $400 \mathrm{mg}(2 \times 200 \mathrm{mg})$. 


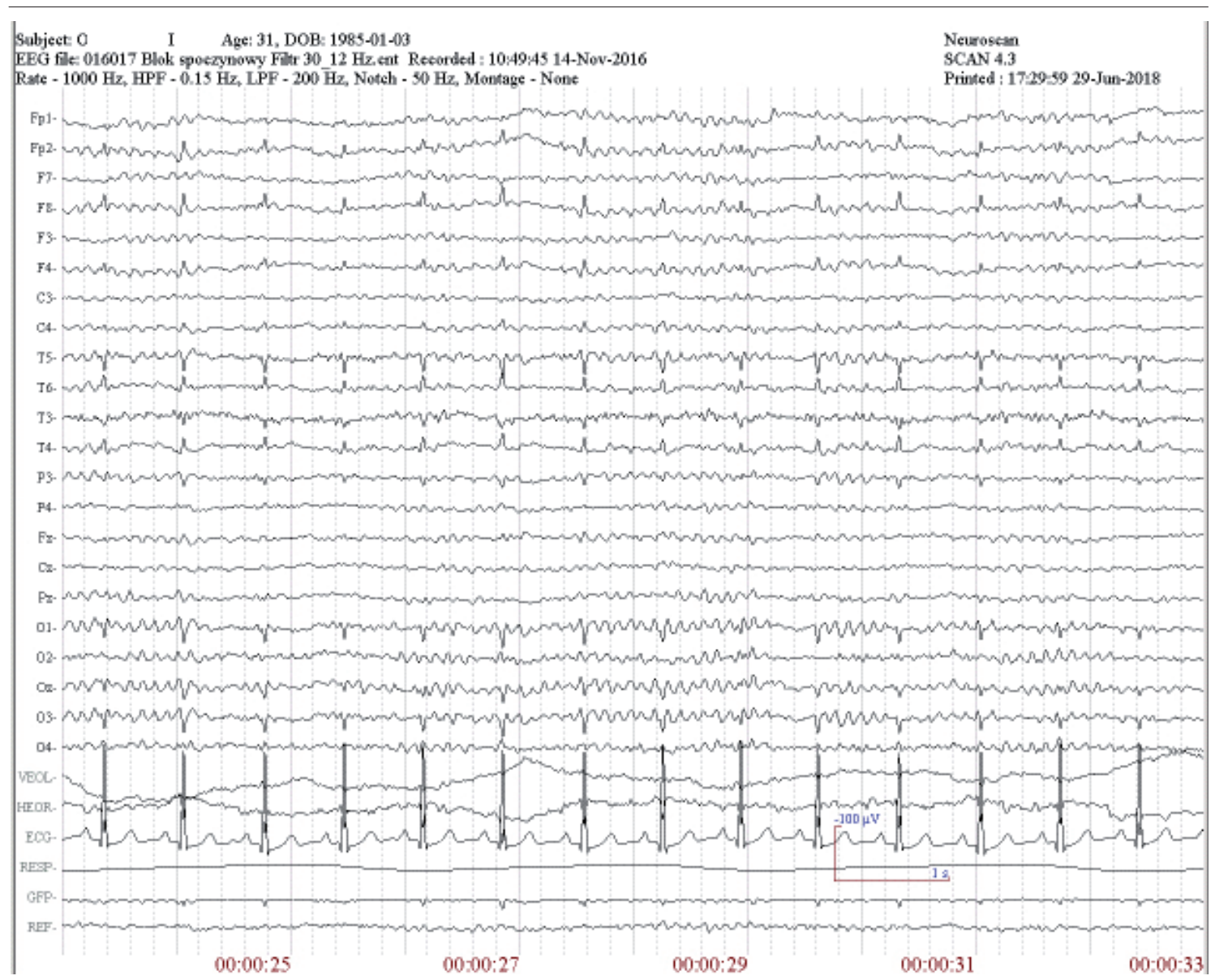

Fig 2. Fragment of follow-up EEG No. 016070 of 14 November 2016.

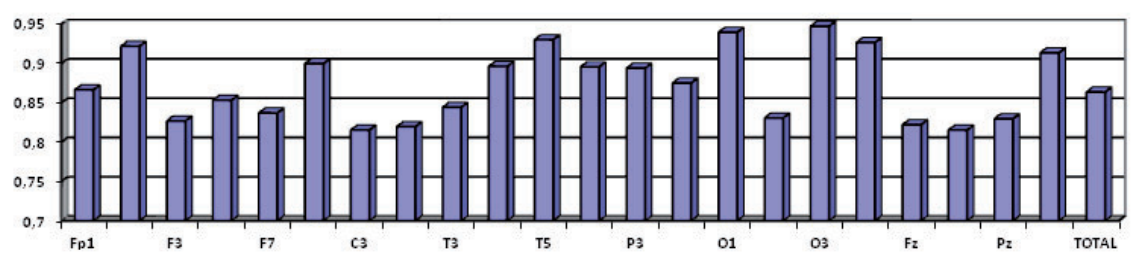

Fig. 3a. QEEG examination No 014150. Resting record. Pearsons' frequency analysis of the bioelectric brain signal (Aver Frequency Domain)

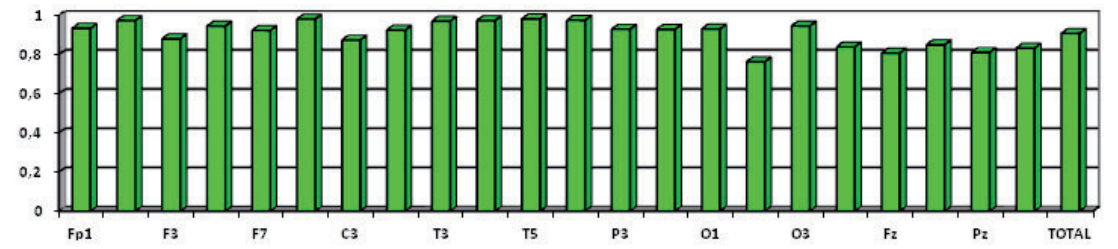

Fig. 3b. QEEG examination No 016017. Resting record. Pearsons' frequency analysis of the bioelectric brain signal (Aver Frequency Domain)

The EEG basic activity was maintained. The QEEG analysis is dominated by alpha rhythm of $9.8 \mathrm{~Hz}$ (8.5-9.5 Hz - visual assessment), amplitude up to $30 \mu \mathrm{V}$, with trace low-voltage beta ac- tivity. Alpha activity maintained. Hyperventilation and single intermittent white light stimulation $(2,6,12$ and $18 \mathrm{~Hz})$ did not trigger the bioelectric brain function, it did not change the character 


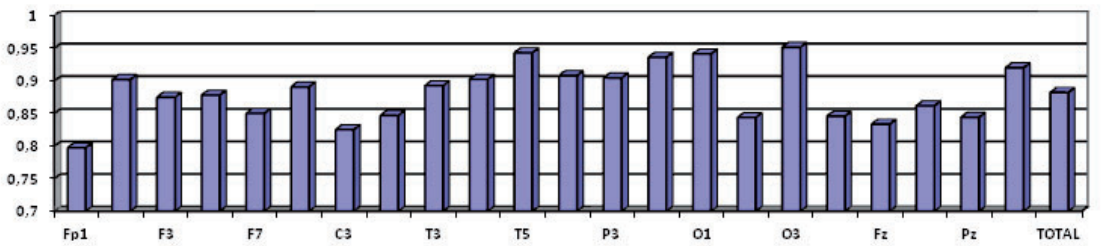

Fig. 4a. QEEG examination No. 014150. Resting record. Intra-Class Correlation analysis of the frequency of bioelectric brain signal (Aver Frequency Domain).

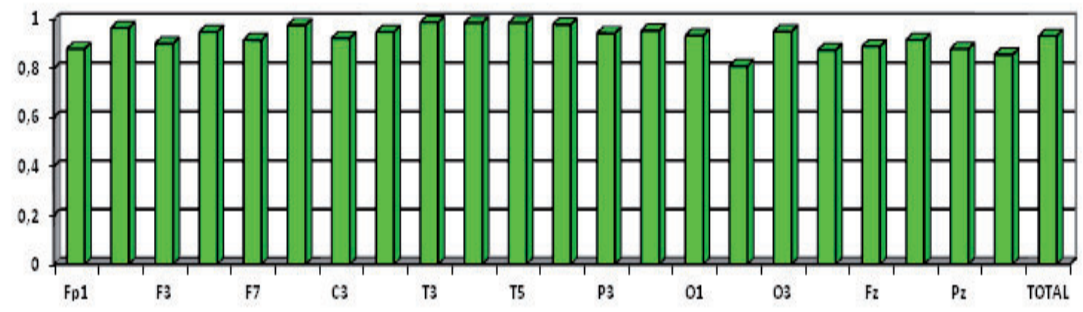

Fig. 4b. QEEG examination No. 016017. Resting record. Intra-Class Correlation analysis of the frequency of bioelectric brain signal (Aver Frequency Domain).

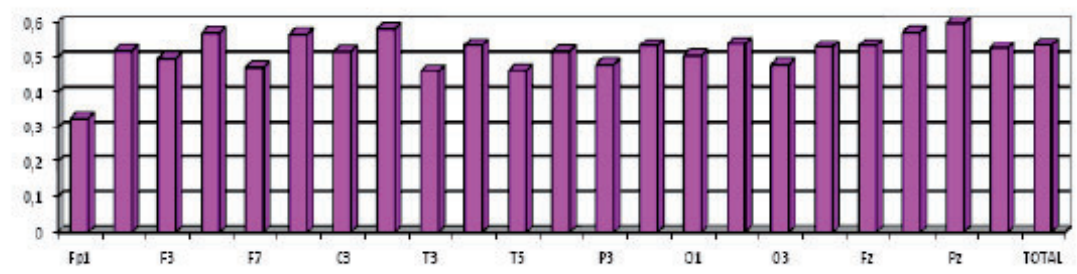

Fig. 5a. QEEG examination No. 014150. Resting record. Intra-Class Correlation analysis in the time domain (Aver Time Domain).

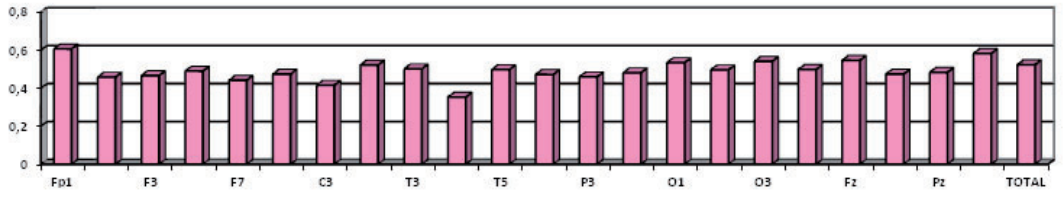

Fig. 5b. QEEG examination No 016017. Resting record. Analysis by Intra-Class Correlation method in the time domain (Aver Time Domain).

of the EEG recording. Despite the two-year gap between the QEEGs (carried out on the same day of the menstrual cycle, in the morning) the basic features of the dominant alpha rhythm did not change; $9.8 \mathrm{~Hz}$ and amplitude up to $30 \mu \mathrm{V}$. The character of cardiac artifacts has not changed as well over the two years. No muscular artifacts were recorded.

Pearsons' frequency analysis of the bioelectric brain signal - Aver Frequency Domain (fig. 3a, $3 b)$. The values above the mean (TOTAL $=0.864$ ) in the frequency domain occur in the right frontal region, temporal regions (left predominance) and occipital regions (left predominance). They are close to the maximum "unity" value (,1").

Intra-Class Correlation analysis of the frequency of bioelectric brain signal - Aver Frequency Domain (fig. 4a, 4b). Highest correlation coefficient above average (0.882). Indicates in order; for the occipital region $(l>p)$, temporal region $(l j>p)$, parietal region $(p>1)$ and right frontal.

Comparative analysis of resting QEEG results, before starting treatment and after two years of treatment, using two different methods, Pearsons (fig. 3a, 3b) and Intra-Class Correlation (fig. $4 a, 4 b)$, of the averaged brain bioelectrical signal frequency -Aver Frequency Domain, shows a def- 


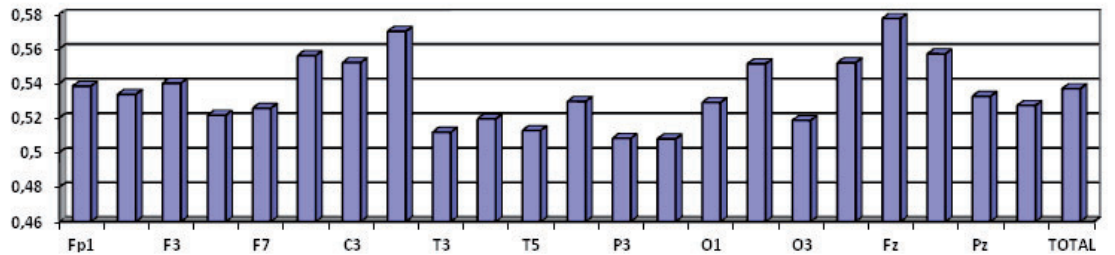

Fig. 6a. QEEG examination No. 014150. Resting record. Intra-Class Correlation analysis of signal power (Spectrum Power).

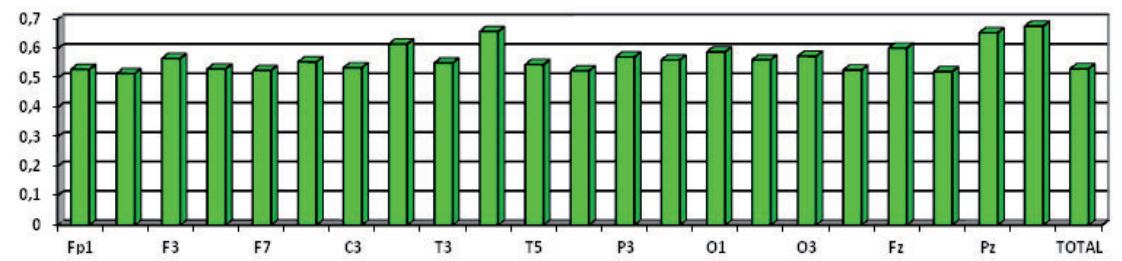

Fig. 6b. QEEG examination No. 016017. Resting record. Intra-Class Correlation analysis of signal power (Spectrum Power).

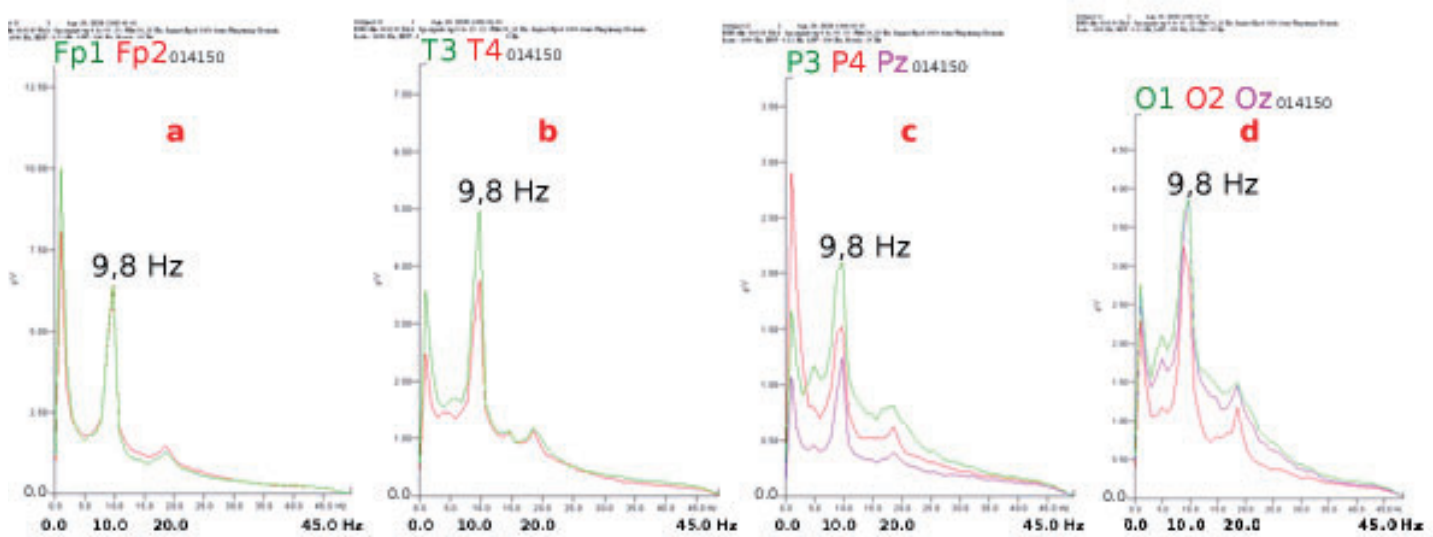

Fig. 7. QEEG no. 014150 in the frequency domain of the bioelectrical brain signal (Aver Frequency Domain). Resting records of selected regions.
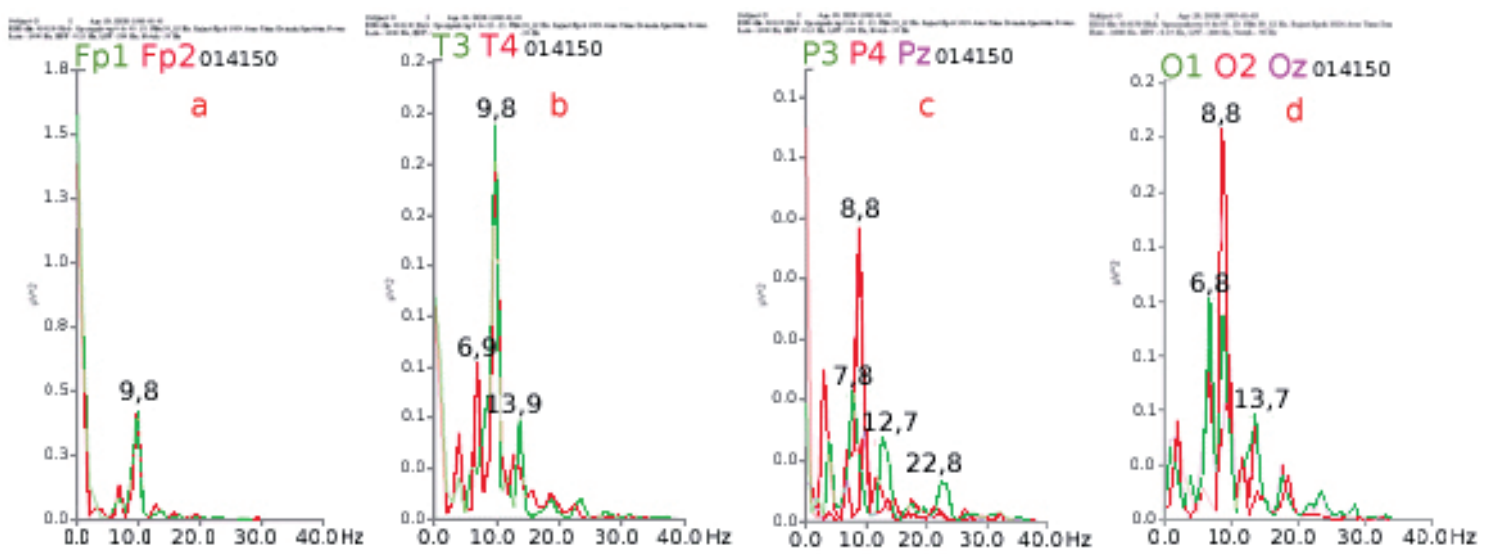

Fig. 8. QEEG examination No. 014150. Analysis of the power of signal bioelectric of the brain. Spectrum Power resting record of selected regions.

inite improvement in the activity - normalization of recorded brain bioelectrical frequencies in the follow-up examination carried out after two years. In most regions the signal value is higher than the average and close to the maximum, i.e. "1".
The lowest values of the correlation coefficient were found in the left frontal region. In other leads the values oscillate around the average of 0.536 . 

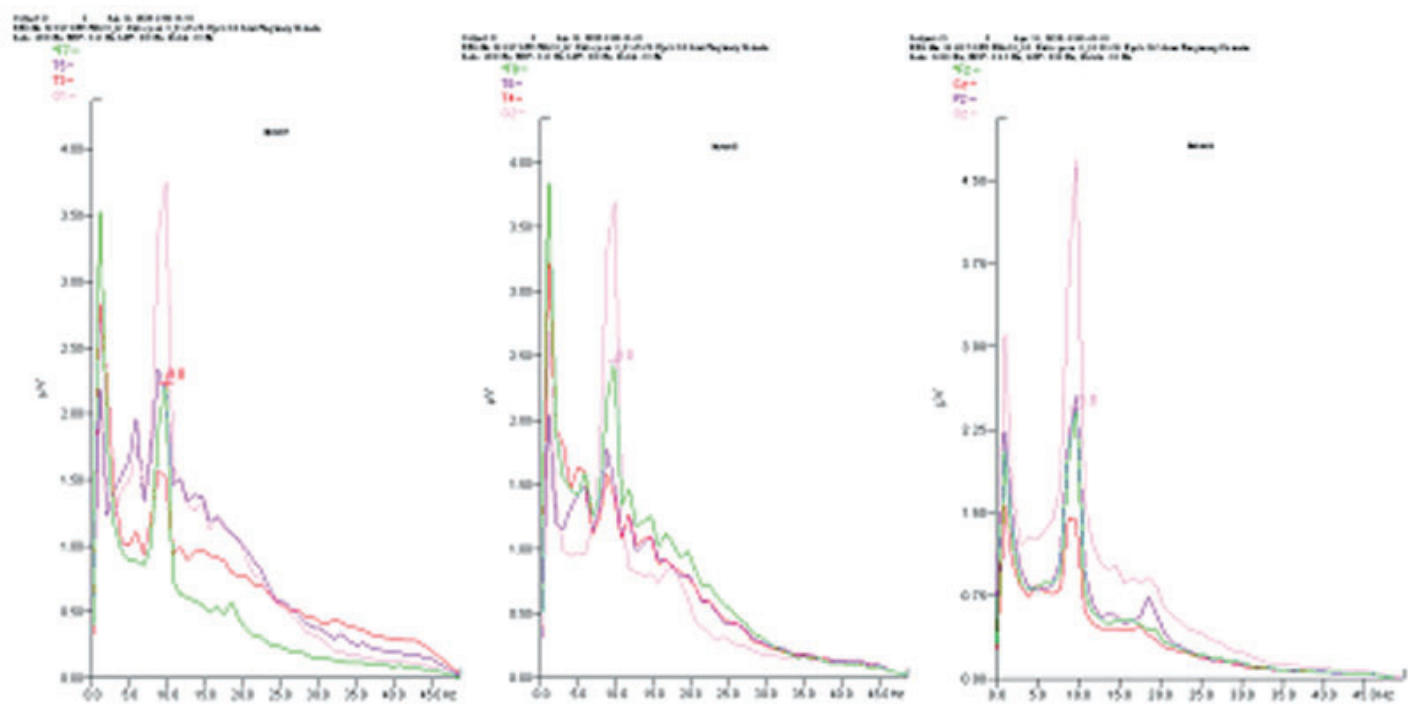

Fig. 9. QEEG examination no. 016017 - Aver Frequency Domain. Resting records of selected regions.
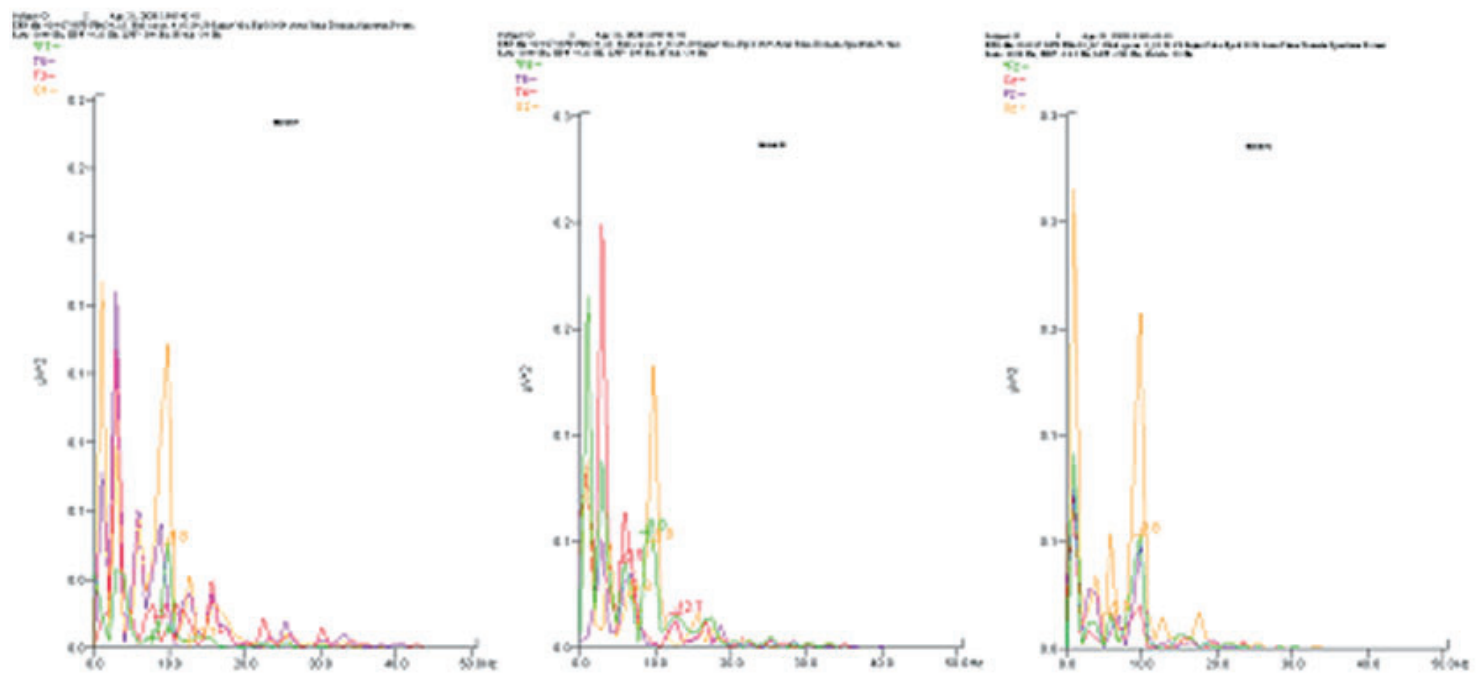

Fig.10. QEEG examination no. 016017 - Spectrum Power. Resting records of selected regions.

The lowest values were found in the right temporal region. In other leads the values oscillate around the average of 0.523 .

The Intra-Class Correlation indicators of both QEEG results no. 014150 (fig. 5a) and no. 016017 (fig. $5 b$ ) in the time domain (Aver Time Domain) reach values slightly above $50 \%(0.536$ and 0.523 respectively) and are close to each other. Significant improvement (by 50\%) occurred in the left frontal region.

The average values of the Intra-Class Correlation indicators of both QEEG results no. 014150 and no. 016017 , in the range of bioelectric signal power, are almost the same $(0.536$ and 0.531 respectively). In the first QEEG examination - no. 014150 (fig. 6a), brain bioelectric signal power of less than
$50 \%$ of the average value was recorded in the middle area. Temporal region except the middle temple of the left cerebral hemisphere and the parietal region of the brain. In the other areas (anterior and posterior), the bioelectric signal power of the brain reaches more than $50 \%$. In the followup QEEG examination no. 016017 (fig. 6b), in all regions of the brain, the bioelectric signal power is above $50 \%$ and is close to each other, stabilization has occurred. This may indicate, among other things, that the treatment has a positive effect. Significant improvement (50\%) is observed in the frontal area of the left and the entire central area.

Figures no. 7 and 8 present graphical analysis of the frequency and power of the bioelectric signal in the first QEEG examination no. 014150 
carried out before starting treatment, during the occurrence of the episodes of weakness accompanied by a temporary loss of consciousness, during spontaneous laughter. The analysis of bioelectric signal frequency does not indicate any significant differences in transverse and longitudinal leads of the two hemispheres. Signal power analysis for all QEEG topolocalization leads shows a reduction in power with a shift to lower $(>6 \mathrm{~Hz})$ and higher $(>13 \mathrm{~Hz})$ frequencies, in the middle and rear area (temporal, central, parietal and occipital areas). In the front and rear area, the dominant signal power coincides with the dominant frequency of $9.8-8.8 \mathrm{~Hz}$.
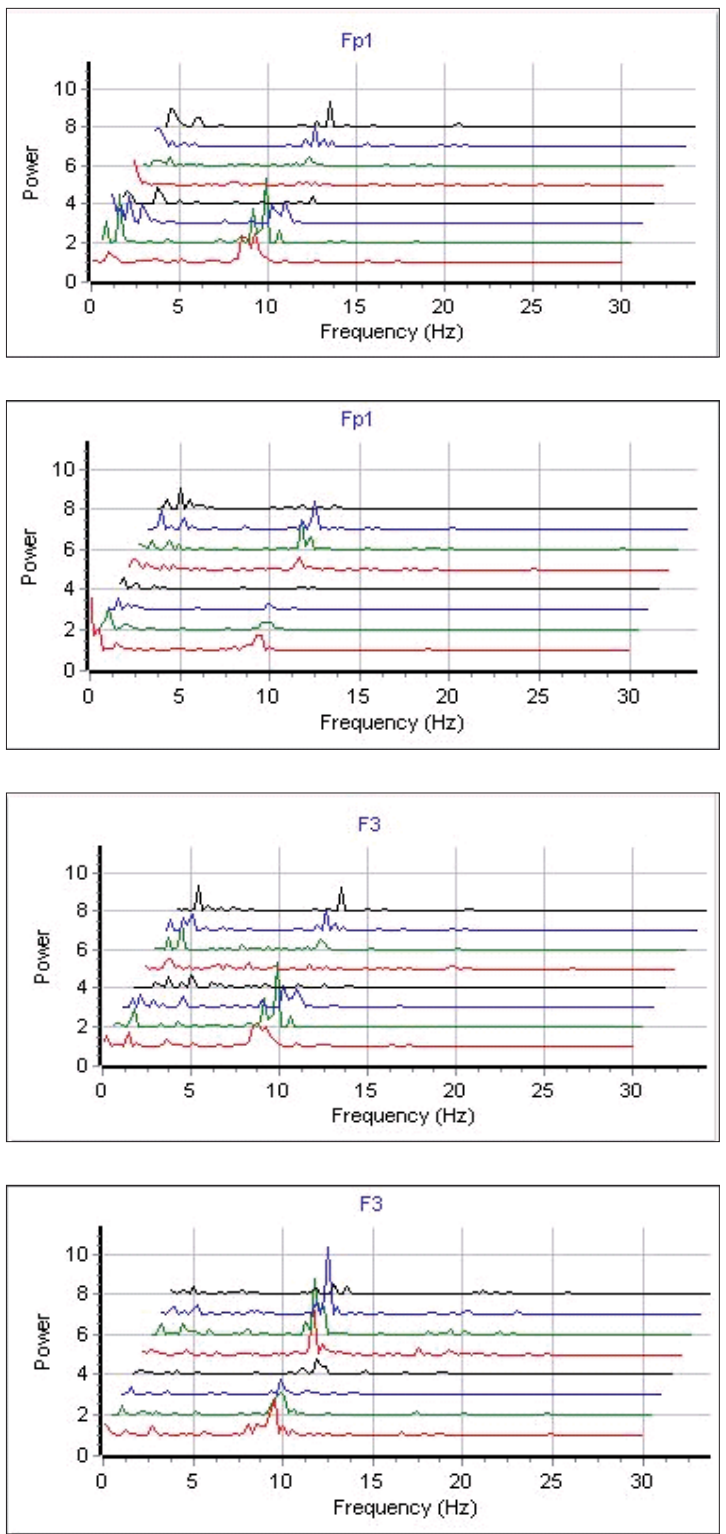

Figure no. 9 and 10 present a graphical analysis of the frequency and power of the bioelectric signal in the QEEG follow-up examination after 23 months during the Tegretol CR 200 treatment $(2 x$ $200 \mathrm{mg}$ ). After a period of 22 months from the last episode of collapsing, accompanied by a temporary disturbance of consciousness, during a spontaneous laughter. The analysis of bioelectric signal frequency does not indicate any significant differences in transverse and longitudinal leads of the two cerebral hemispheres, also in comparison with the results of the analysis of the first QEEG examination No. 014150, before the beginning of treatment. The signal power analysis for all
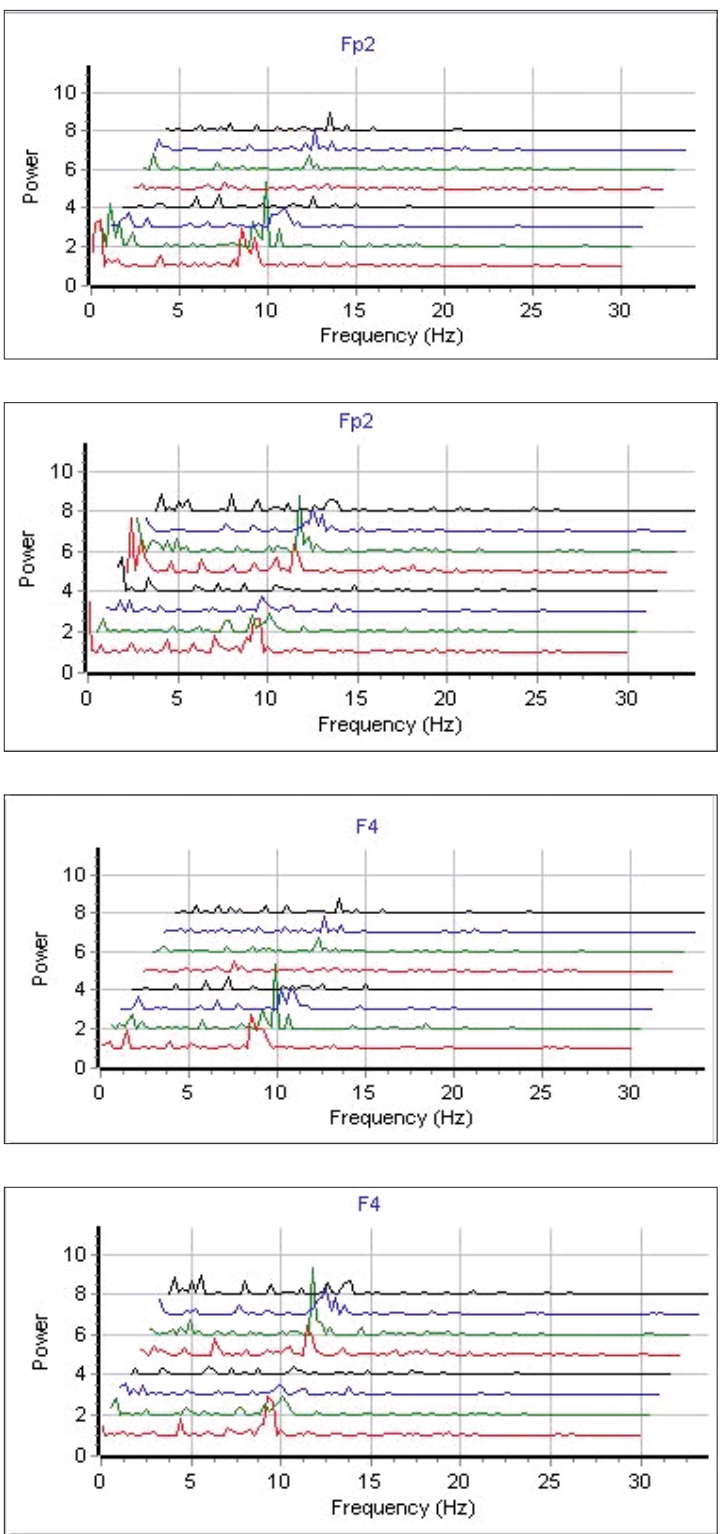

Fig. 11. Comparative time-space analysis of power and frequency of bioelectrical signal for individual brain regions (22 leads) of resting QEEG no. 016017 (top Figures - after treatment) with resting QEEG no. 014150 (homologous regions in bottom Figures - before treatment). 
Dec S. - Loss of consciousness...
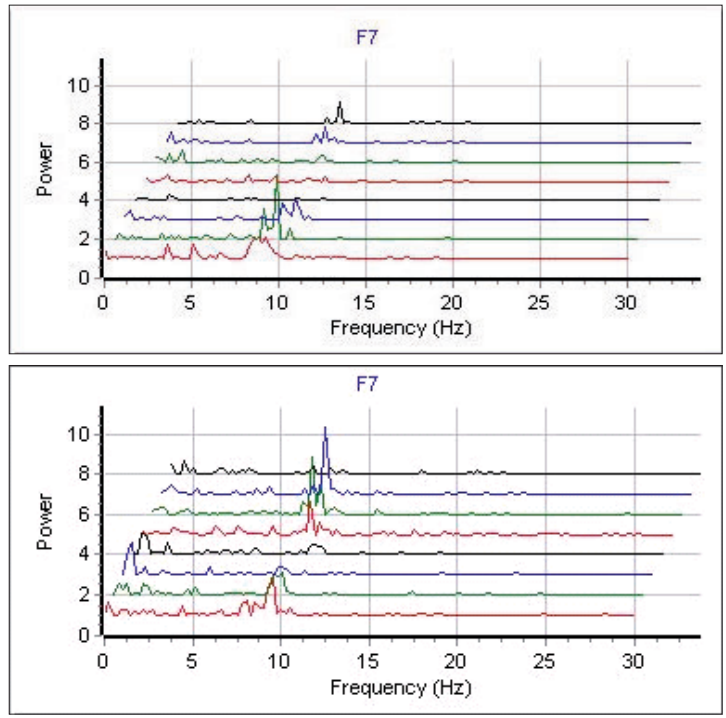

$\mathrm{C} 3$
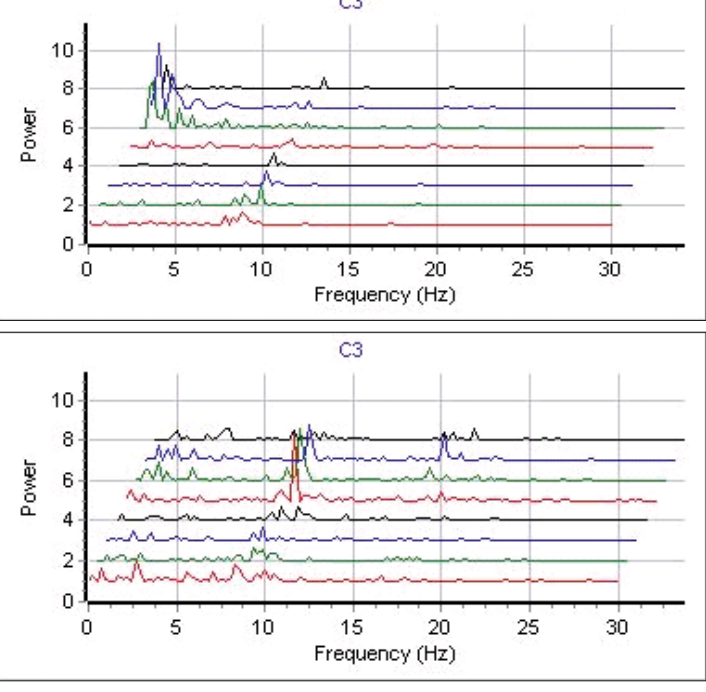

T3

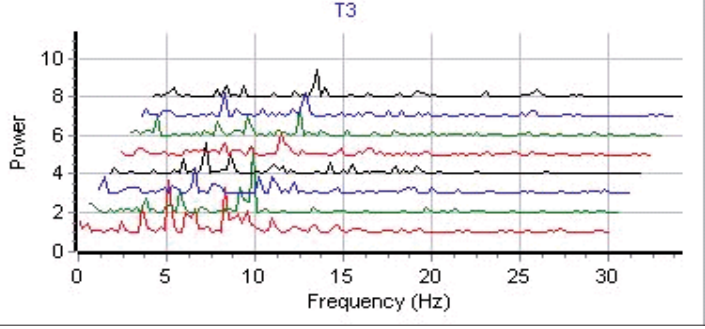

T3

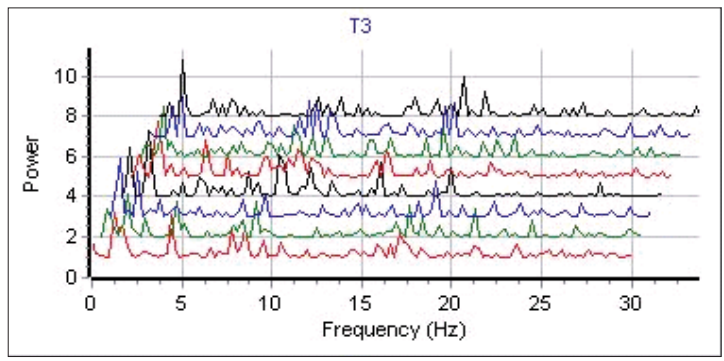

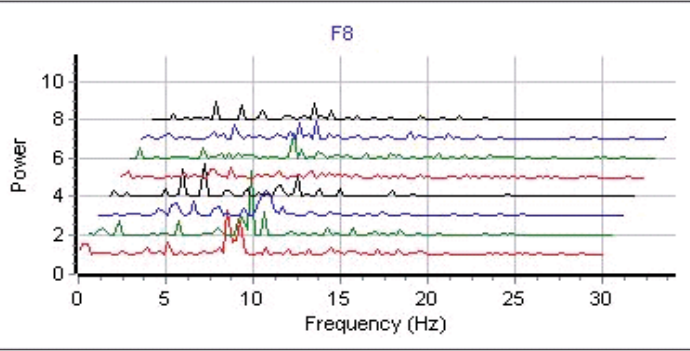

F8

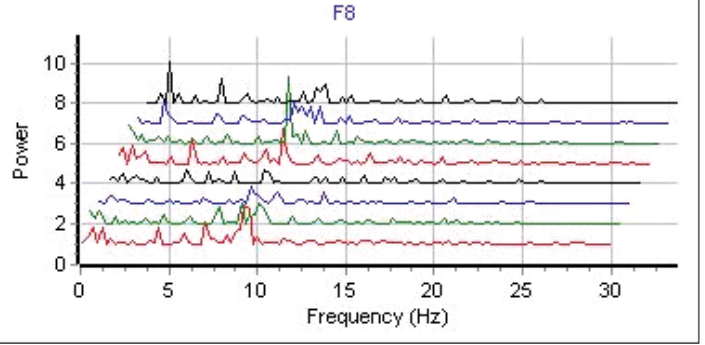

$\mathrm{C} 4$

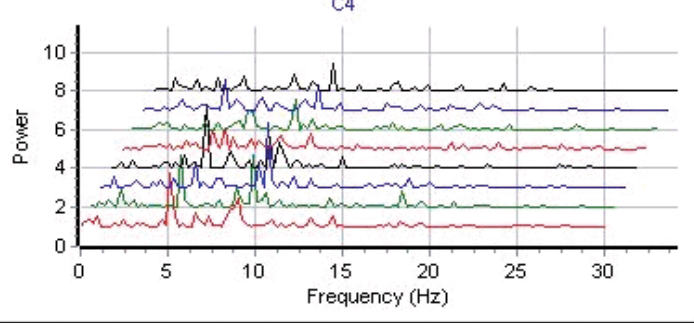

C4

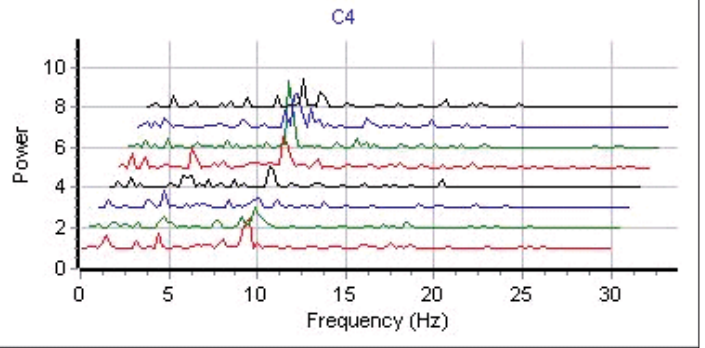

T4
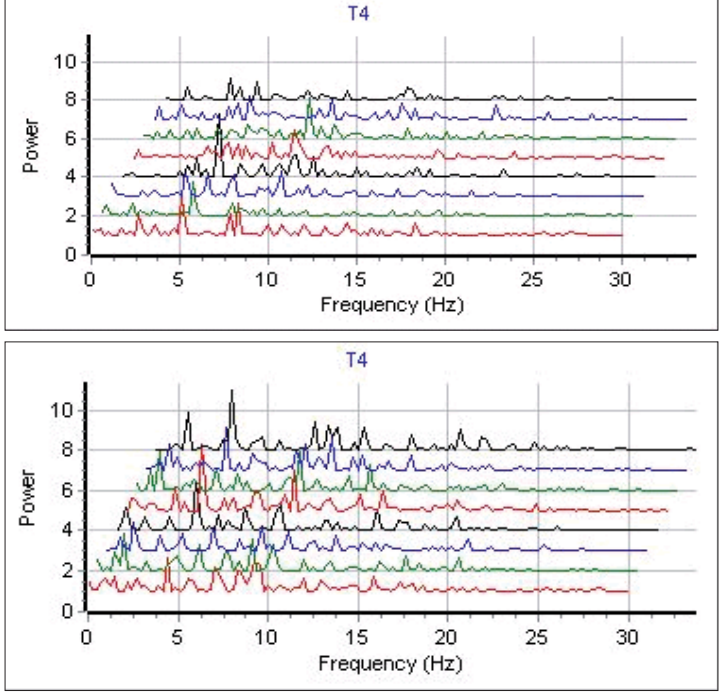

Fig. 11. Comparative time-space analysis of power and frequency of bioelectrical signal for individual brain regions (22 leads) of resting QEEG no. 016017 (top Figures - after treatment) with resting QEEG no. 014150 (homologous regions in bottom Figures - before treatment). 

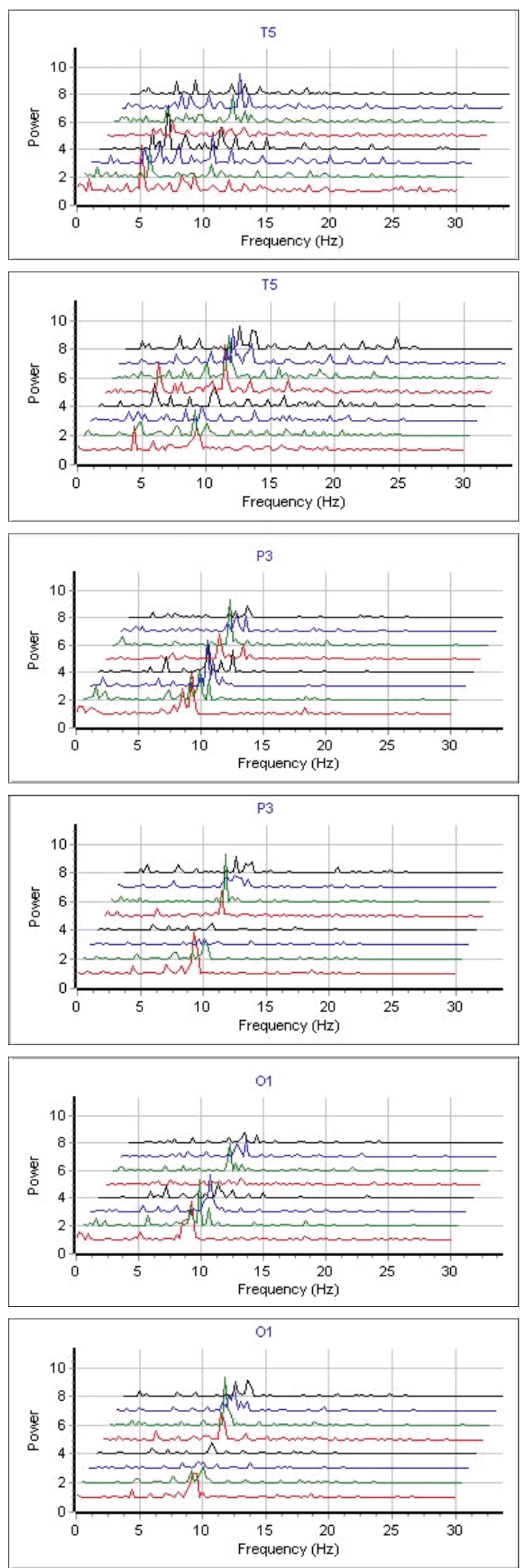
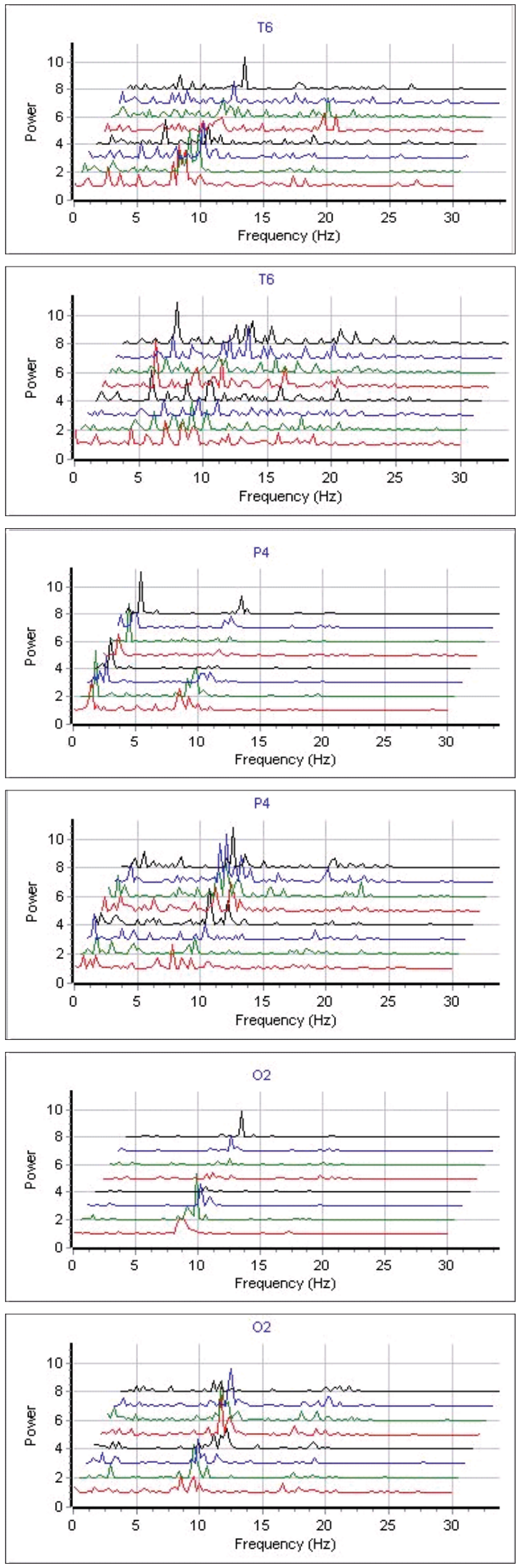

Fig. 11. Comparative time-space analysis of power and frequency of bioelectrical signal for individual brain regions (22 leads) of resting QEEG no. 016017 (top Figures - after treatment) with resting QEEG no. 014150 (homologous regions in bottom Figures - before treatment). 
Dec S. - Loss of consciousness...
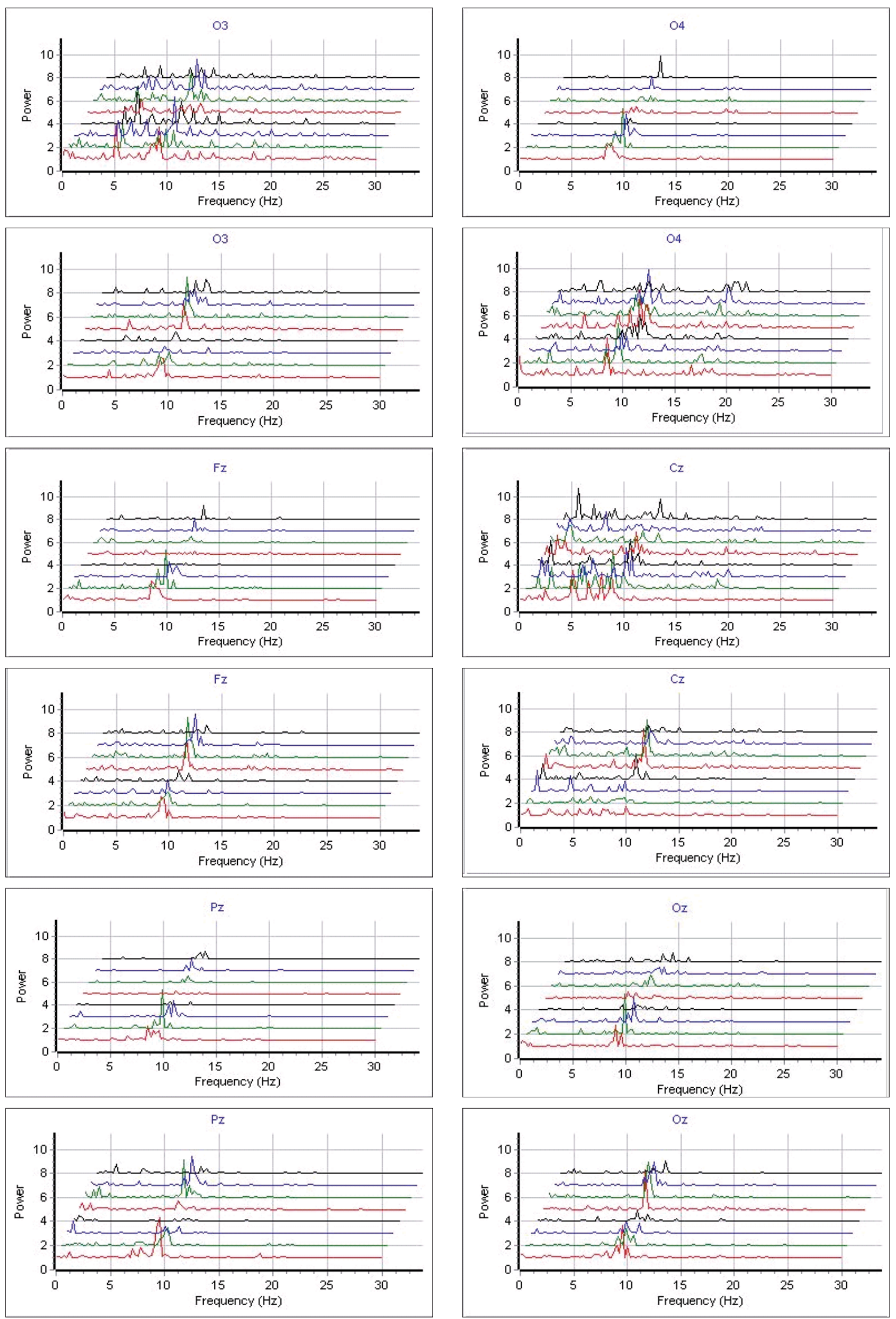

Fig. 11. Comparative time-space analysis of power and frequency of bioelectrical signal for individual brain regions (22 leads) of resting QEEG no. 016017 (top Figures - after treatment) with resting QEEG no. 014150 (homologous regions in bottom Figures - before treatment). 
QEEG topolocalization leads shows that the power is consistent with the dominant frequency. The significant power range of the brain bioelectric signal narrowed from $6-23 \mathrm{~Hz}$ (first QEEG examination no. 014150 before starting the treatment) to $6-18 \mathrm{~Hz}$. In addition to the graphical EEG recording, objective mathematical analyses confirm the improvement of bioelectrical brain activity. This may indicate a positive influence of the treatment on the normalization (organization) of the bioelectric activity in the patient's brain.

Another method used - time-space analysis of power and frequency of bioelectrical signal of the brain (fig. 11), shows an objective positive improvement in EEG results, especially in the middle and rear area of the brain.

\section{SUMMARY}

After a period of 23 months during which the patient was taking Tegretol CR 200 ( 2 × 200 mg per day), follow-up QEEG was performed in November, on the same day of the menstrual cycle as the first examination. QEEG examination No. 016070 (fig. 2), was performed following a decision to gradually reduce the dose of Tegretol CR from $400 \mathrm{mg}$ per day by $1 / 4$ per month until complete discontinuation of the treatment. In the period of 23 months (from the end of December 2014 to 16 November 2016) no episodes of fainting with accompanying loss of consciousness, or other similar symptoms occurred. Throughout this period, the patient felt fine, had no ailments and functioned normally. The analysis of follow-up QEEG no. 016017 indicated a dominant alpha rhythm of $9.8 \mathrm{~Hz}$ (8.5-9.5 $\mathrm{Hz}$ - visual assessment), amplitude up to $30 \mu \mathrm{V}$, with a trace low-voltage beta activity. Alpha activity maintained. Hyperventilation and single intermittent white light stimulation $(2,6,12$ and $18 \mathrm{~Hz})$ did not trigger the bioelectric brain function, it did not change the character of the EEG recording.

Despite the two-year gap between the QEEGs (carried out on the same day of the menstrual cycle, in the morning) the basic features of the dominant alpha rhythm did not change $(9.8 \mathrm{~Hz}$ and amplitude up to $30 \mu \mathrm{V}$ ) [10]. The character of cardiac artifacts has not changed as well over the two years. No muscular artifacts were recorded in the follow-up QEEG examination. Due to the fact that there were no complaints, the patient had previously stopped the Calperos treatment on her own (after $>$ half a year of taking). Comparative statistical analyses using Pearsons and Intra-Class Correlation (fig. 3-6) in the domain of frequency, time and power of brain bioelectrical signal and medical imaging in the range of averaged frequency, time and power of brain bioelectrical signal (fig. 7-11) indicated significant improvements in the recording of brain bioelectrical activity in all the methods.

Preventive inclusion of Tegretol in the treatment was guided by the patient's intense lifestyle, especially social life, the nature of her professional work (classes with students), lack of complete assessment of the events (by the leading neurologist), revealing certain symptoms indicating the possibility of the patient's insubordination, which was confirmed during the treatment. The psychological examination was abandoned (the patient is an academic teacher, practicing as a psychologist).

During the case diagnosis tetany, epilepsy and cardiac disorders were considered [4,5,7,11]. Based on the analysis of the patient's symptoms and additional tests, the most important criteria suggest latent tetany. Young age (29 years), sex, physiologically unfavorable period (beginning of the menstrual cycle), season (autumn-winter), low sunlight exposure. A shortage of sunlight reduces the body's natural production of vit. $D$ and has a negative effect on the bioelectrical activity of the brain. Paroxysmal weakness with accompanying loss of consciousness, preceded by a feeling of numbness around the mouth, tingling and numbness of upper and lower limbs - especially fingers (tendency to stiffening), paling of the skin without cyanosis. Preceding a dozen or few dozen seconds of parahyperventilation in the course of spontaneous, expressive laughter $[3,6,8,8,12,13]$. Lower limit values of PTH, Ca, Mg, vit. D $[9,11,16]$. Ischemic test - low positive and the QEEG results (objective multiple mathematical analyses) $[1,2,10]$. The variety of mathematical methods used for the analysis of the EEG results was aimed at the maximum possible exclusion of causes of the above-mentioned episodes other than tetany, using a small number of QEEG (two examinations).

\section{AUTHORS' DECLARATION:}

Study Design: Stanisław Dec; Data Collection: Stanisław Dec; Manuscript Preparation: Stanisław Dec; Funds Collection: Stanisław Dec. The Author declares that there is no conflict of interest. 
Dec S. - Loss of consciousness...

\section{REFERENCES}

1. Blinowska KJ. Malinowski M. Non-linear and linear forecasting of the EEG time series. Biological Cybernetics. 1991; 66(2):159165.

2. Blinowska K. Zagadnienia cyfrowej analizy przebiegów fizjologicznych. Rozprawa habilitacyjna. Wydawnictwa Uniwersytetu Warszawskiego, Warszawa 1980.

3. Bradley D. Hyperventilation syndrome. Auckland, New Zealand: Tandem, 1991; and Berkeley, California: Ten Speed Press, 1992.

4. Bradley WG, Daroff RB, Fenichel GM, Jankovic J. Neurologia w praktyce klinicznej. Zaburzenia kliniczne. T.III. Wyd. Czelej Sp. z o.o. Lublin 2007; 332-363.

5. Delvaux M, Fontaine P, Bartsch P, Fontaine O. Tetany, spasmophilia, hyperventilation syndrome: theoretical and therapeutic synthesis. Rev Med Liege. 1998; 53(10), 610-618.

6. Dowgiałło M. Obniżenie progu pobudliwości nerwowo-mięśniowej u zdrowych osobników. Nieopublikowana praca doktorska. A.M. Warszawa 1962.

7. Durlach J, de Vernejoul F, Poenaru S, Reba A, Henrotte JG. Tetanie latente au cours d'un deficyt magnesique chronique et prolapsus idiopathique de la valve mitrale (Barlow's disease): correlation entre donnees cliniques et echocardiographiques. Magnesium-Bull. 1981; 3(1b):25-26.

8. Durlach J. Magnez w praktyce klinicznej. Wydawnictwo Lekarskie PZWL. Warszawa 1991; 43-50, 83-91, 74-78.

9. Kokot F, Tatoń J. Zaburzenia przemiany materii. W: Choroby wewnętrzne : podręcznik akademicki. Franciszek Kokot (red.). Wyd. 8, T. 2. Wydawnictwo Lekarskie PZWL. Warszawa 2004.

10. Miszczak J. Przestrzenno-czasowa analiza aktywności bioelektrycznej mózgu. Elektroencefalografia Kliniczna. PSWL, Warszawa 1989; 37, 252.

11. Myśliwiec H, Myśliwiec M. Rola witaminy D w ustroju. Medycyna po Dyplomie. 2007; 16(9):130-135.

12. Rabe-Jabłońska J. Ataki paniki. Zaburzenie paniczne i panikopodobne. Łódzki Biuletyn Neurologiczny 1997; 1, 2.

13. Rolak LA. Sekrety neurologii. Wyd. D.W. Publishing Co. Szczecin 1996; 21.

14. Rowland LP. Neurologia Merritta. Wyd. Elsevier Urban \& Partner. Wrocław 2004; 816-836.

15. Rowland LP. Neurologia Merritta. Wyd. Elsevier Urban \& Partner. Wrocław 2004; 760-761, 862.

16. Szczeklik A. Choroby wewnętrzne. Podręcznik multimedialny oparty na zasadach EBM. T. 1. Wydawnictwo Medycyna Praktyczna. Kraków 2005.

Cite this article as: Dec S. Loss Of Consciousness During Spontaneous Laughter. Pol J Aviat Med Bioeng Psychol 2018; 24(1): 33-47. DOI: 10.13174/pjambp.06.08.2019.04 